\title{
A telemetric device for measuring smoking topography
}

\author{
WAYNE KASHINSKY, BRADLEY N. COLLINS, and THOMAS H. BRANDON \\ State University of New York, Binghamton, New York
}

\begin{abstract}
The Telemetric Topography Device (TTD) introduces new technology to the measurement of cigarette smoking topography that has advantages over existing instruments. It consists of a 90.8-g

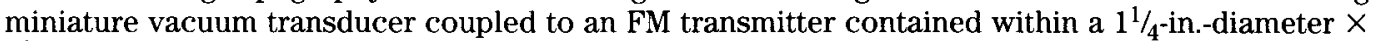
$4^{1 / 4}$-in. free-standing plastic cylinder. As a subject smokes through a modified commercial cigarette holder, the TTD transmits a tone proportional to the vacuum pressure change in the cylinder. Received tones are converted to voltage data and then digitized by an A/D board in a personal computer. This information can either be displayed and stored on line or recorded on audio tape and digitized during playback. The TTD has no visible electronic parts, thereby minimizing subjects' awareness of monitoring.
\end{abstract}

The term smoking topography refers to the variant features of smoking behavior, such as puff frequency, duration, strength and volume, interpuff interval, and cigarette duration. Because these variables influence nicotine dosage as well as health risks of smoking (i.e., carbon monoxide exposure), they are potentially important to studies of inter- and intrasmoker variability in nicotine self-administration. Researchers have shown that indices of smoking topography vary across situations (Miller, Fredericksen, \& Hosford, 1979) and times of day (Robinson \& Young, 1980). Pomerleau and Pomerleau (1987) also demonstrated that, following experimental manipulation of stress, smokers self-regulate dose and rise time of blood nicotine levels by varying such topographical indices as depth of puff, puff frequency, and puff duration. Similarly, manipulation of negative affect can also increase the frequency and duration of puffs (Payne, Schare, Levis, \& Colletti, 1991).

Smoking topography provides a more molecular analysis of smoking behavior than do global cigarette consumption measures (Fredericksen, Miller, \& Petersen, 1977). Historically, however, there has been little consistency across studies in terms of which topographic measures, if any, significantly reflect presumed changes in smoking motivation (see, e.g., Brandon, Wetter, \& Baker, in press; Epstein, Ossip, Coleman, Hughes, \& Wiist, 1981; Hatsukami, Pickens, Svikis, \& Hughes, 1988; Payne et al., 1991). In this paper, we will briefly re-

This research was supported by Grant JFRA389 from the American Cancer Society and Grant 92-024GB from the American Heart Association, New York State Affiliate, awarded to Thomas Brandon. We thank Jed Rose for his suggestions concerning calibration of the instrument. Correspondence concerning this article should be addressed to T. H. Brandon, Department of Psychology, State University of New York at Binghamton, Binghamton, NY 13902-6000 (e-mail: brandon@ bingvmb.cc.binghamton.edu). Copies of the computer software are also available. view some of the instruments and methods used to measure smoking topography, and we will then describe a technological advance, the Telemetric Topography Device (TTD), that reduces the limitations of previous instruments used in this area of smoking research. ${ }^{1}$

The most common method of assessing smoking topography includes unobtrusive videotaping (see, e.g., Fredericksen, Martin, \& Webster, 1979). However, when experimenters rely solely on trained observer scoring of videotaped temporal topography data, many topographical indices (e.g., puff volume) remain ignored. Therefore, researchers have sought to obtain more complete and reliable topography data.

Recently developed topography instruments offer such comprehensive and reliable assessment strategies. A typical instrument consists of a cigarette holder attached to a box by a flexible plastic tube. The box contains a pressure switch and circuitry that digitizes the temporal smoking topography data, which are then transferred to a computer (see, e.g., Pickens, Gust, Catchings, \& Svikis, 1983). Similar portable devices can be used outside the laboratory (see, e.g., Hatsukami, Morgan, Pickens, \& Champagne, 1990). Many of these devices, however, only measure temporal characteristics of smoking (i.e., puff length, interpuff interval), and not other topographic variables that also influence nicotine intake, such as puff strength or volume.

To obtain even more complete topography data, therefore, some researchers have used plethysmographs to record thoracic movement as an analogue of puff volume (e.g., Tobin \& Sackner, 1982; Zacny, Stitzer, Brown, Yingling, \& Griffiths, 1987). Other researchers developed cigarette holders attached to pressure or flow transducers (e.g., Epstein et al., 1981; Henningfield \& Griffiths, 1979). A subject smokes through a holder attached to the transducer while holding the transducer. A cable passes from the transducer to the polygraph or computer, and pressure changes are analyzed in order to de- 
termine temporal parameters as well as puff strength and volume. A similar device, such as that used by Rawbone, Murphy, Tate, and Kane (1978) and Creighton, Nobel, and Whewell (1978), measures draw resistance across two pressure transducers in a modified cigarette filter.

The major drawback of the topography instruments cited thus far, however, is that they are often cumbersome and awkward to use. They typically have cords tethered to a computer or recording device, and they hardly encourage the natural behavior sequence associated with smoking. Hence, a gain in precision may lead to a loss in the external validity of topographical data.

The most promising of devices that avoid the bulkiness problem was developed by Puustinen, Olkkonen, Kolonen, and Tuomisto (1987). With this device, all puff data are analyzed by a portable orifice flow meter housed within a cigarette holder. A differential transducer measures pressure differences in the flow meter that can be used to calculate flow rate of smoke, puff duration, single puff volume, puff volume per cigarette per day, interpuff intervals, and number of puffs. These data are automatically stored on a microcassette via an analog/ digital (A/D) converter and can later be replayed and converted to computer for analysis. This device also has the advantage of being relatively small and portable. Yet even though the device is much smaller and more sophisticated than the other instruments, it also interrupts natural smoking behavior, because the mouthpiece is connected by cords to the recording device.

In contrast, the TTD telemetry technology enables reliable assessment of the temporal puff parameters, as well as puff strength and volume, while remaining relatively unobtrusive. It is currently used in research as a prototype of future devices, which, with microelectronics, could be reduced to the size of a commercial cigarette holder.

\section{Device Description}

The TTD consists of a miniature vacuum transducer and radio transmitter housed in a bored black Delrin cylinder $4^{1 / 4}$ in. tall $\times 1 \frac{1}{4}$ in. in diameter. The device is powered by a $3.6-\mathrm{V}$ NI-CAD rechargeable battery, weighs $90.8 \mathrm{~g}$, and is free standing. There are no visible wires or cords, because the battery and all circuitry are housed within the cylinder. Therefore, the TTD appears to be a small, light-weight canister attached to a cigarette holder (see Figure 1). A modified commercial cigarette holder (taken from an Aquafilter brand tar-and-nicotine filter ${ }^{2}$ ) is attached to a $5 / 16^{-i n}$. tube on top of the cylinder. Subjects can manipulate the device in hand as they wish and inhale on the cigarette through the cigarette holder.

As the subject holds the apparatus, a baseline tone from a voltage-controlled oscillator is transmitted over a clear radio frequency in the FM band $(106 \mathrm{MHz})$. As the subject puffs on the cigarette, the tone frequency shifts upward in proportion to the strength of the puff and returns to baseline afterwards. The radio signal is re-

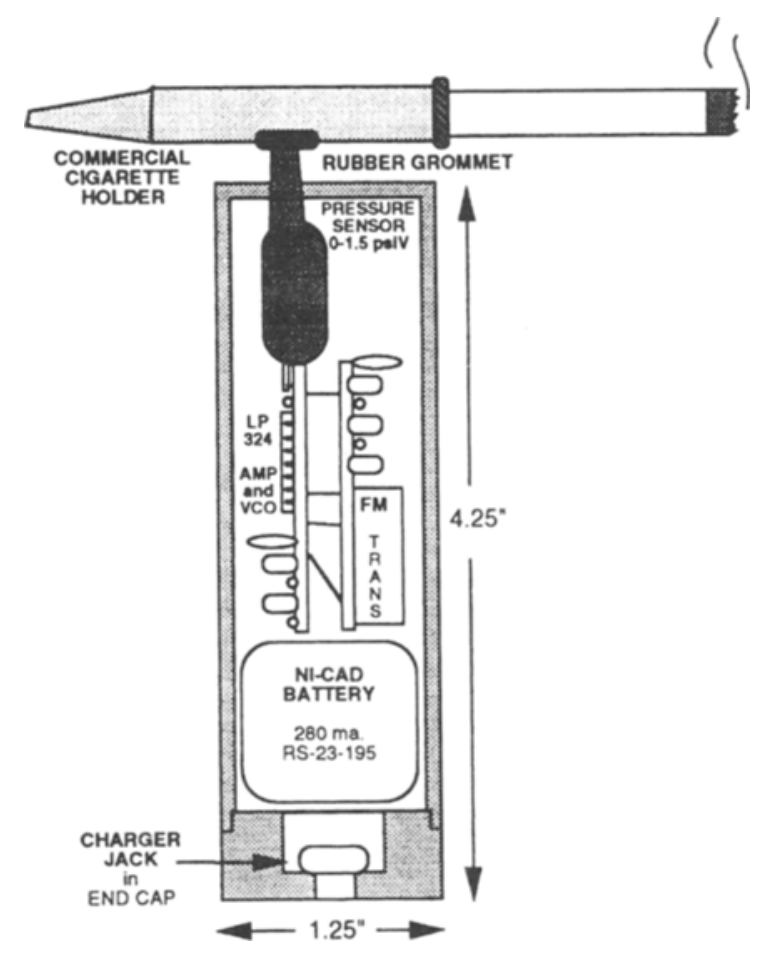

Figure 1. Cross section of canister holding TTD transmitter.

ceived by a local hidden antenna connected to a radio receiver in an adjacent room. This tone can be analyzed on line for real-time recording. It can also be recorded either on audio tape or on the audio channel of videotape and analyzed during playback. A frequency-to-voltage converter generates output that is a linear voltage proportional to the original tone frequency. This voltage can be read on a meter, written to paper with a pen recorder, or sampled with a computer using an $A / D$ converter. (See Figure 2 for the electronic schematics of the TTD and the receiver and tone frequency decoder.)

After recording the tones on tape, we later use an $\mathrm{A} / \mathrm{D}$ converter to digitize the voltage data in real time. A QuickBasic program provides a running timeline graphic display of smoking topography based on tone frequencies ranging from baseline to full vacuum. Another program generates topographical data for each puff as well as summary statistics including latency to first puff, number of puffs, average length of puffs, average interpuff interval, average puff strength, average puff volume, cigarette duration, and time spent puffing in both the first 3 and the first $5 \mathrm{~min}$ after the cigarette is lit. These data can then be exported to a statistical program for analysis.

\section{Accuracy of the TTD}

The accuracy of the TTD was evaluated in two ways. To assess the accuracy of the temporal variables, research assistants hand timed the smoking behavior of 19 subjects (randomly selected from an ongoing study) who had been 


\section{TTD TRANSMITTER}

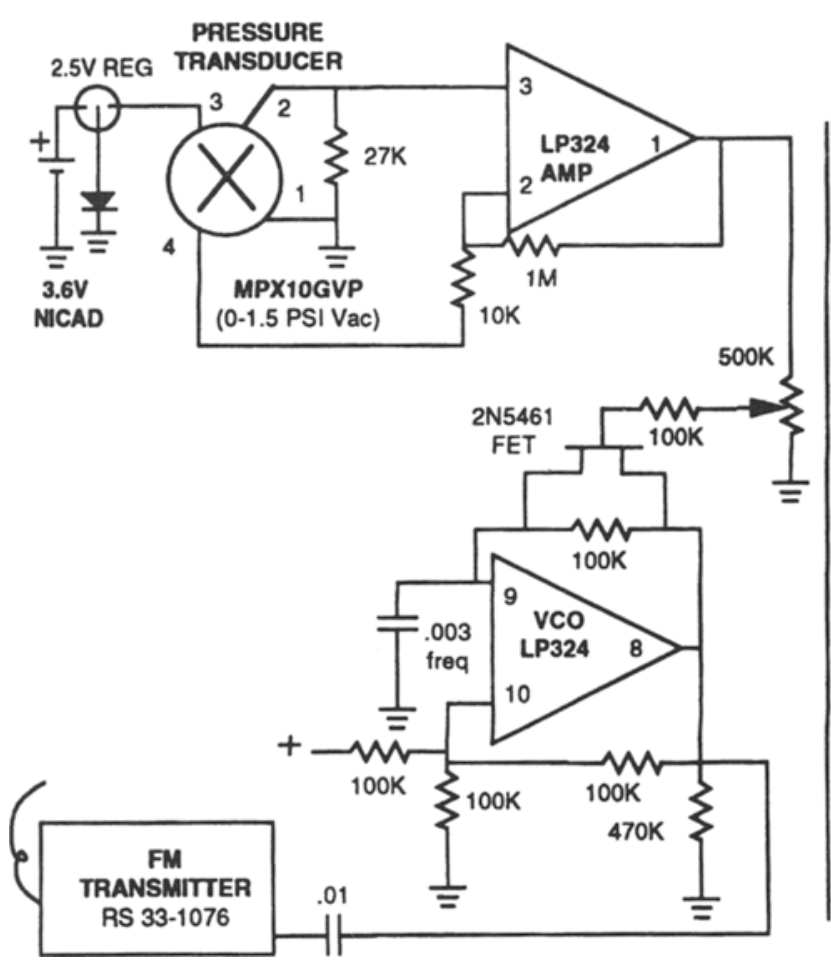

RECEIVER / DECODER

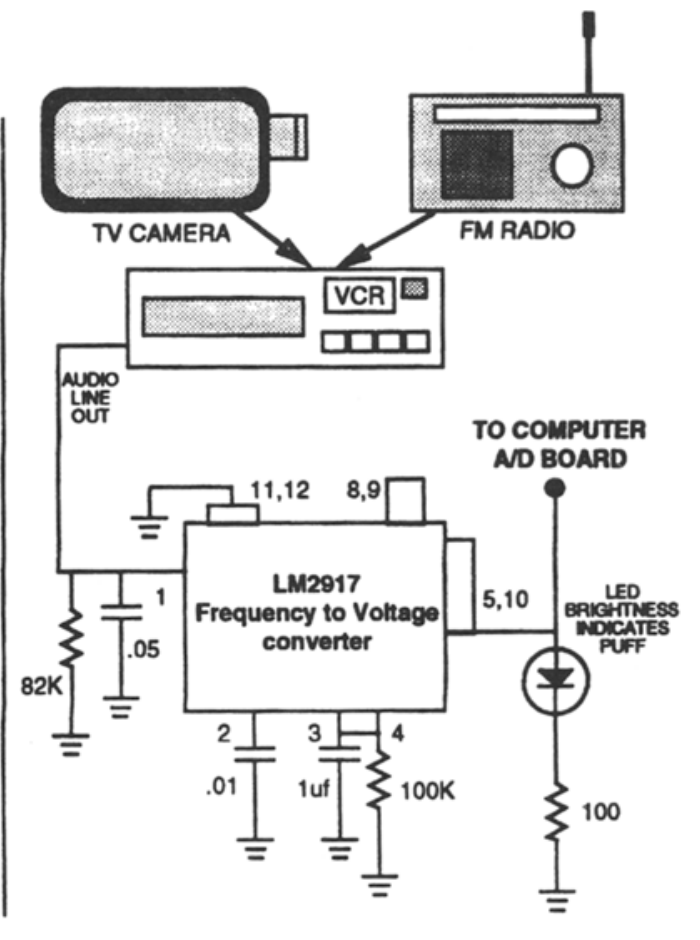

Figure 2. Schematics of TTD transmitter and receiver/decoder.

videotaped while smoking with the TTD. These data were compared with data generated by the TTD itself from the same smoking episodes. As can be seen in Table 1, the two assessment methods yielded comparable data. Correlations between the methods were .84 for puff duration and at least .95 for every other temporal variable (all $p \mathrm{~s}<$ $.001)$. The lower correlation for puff duration probably reflects lower reliability of hand timing (i.e., variable reaction times of the timers) rather than of the TTD.

The values reported in Table 1 are generally within the range reported in other studies in which these variables were measured (U.S. Department of Health and Human Services [USDHHS], 1988, pp. 156-157), although interpuff interval and cigarette duration are higher than had been found in most previous studies. However, it has been reported that mean cigarette duration is longerand equal to our mean-when smokers are observed naturalistically, as opposed to when they smoke in a laboratory using a transducer connected to a polygraph, or in a clinic while being observed obtrusively (OssipKlein, Martin, Lomax, Prue, \& Davis, 1983). This suggests that smoking with the TTD may be more natural than smoking while one is observed or is using a traditional topography device.

The Motorola MXP10GVP vacuum transducer used in the TTD has a manufacturer-specified linearity of $\pm 1 \%$ of full scale, and a stability of $\pm .5 \%$ of full scale. To verify the TTD's accuracy in measuring puff strength and volume, we used a syringe to produce eight vacuum samples across the range of the TTD $(0-37 \mathrm{mg}$ of mer-

Table 1

Means of Temporal Smoking Topography Variables From Hand-Timed Versus TTD-Automated Data Collection, and Previously Reported Ranges for These Variables

\begin{tabular}{lccc}
\hline \multicolumn{1}{c}{ Topography Variable } & Hand-Timed & & Previously Reported \\
\hline Number of puffs per cigarette & Data & TTD Data & Range \\
Latency to first puff $(\mathrm{sec})$ & 8.60 & 8.67 & $8-16$ \\
Puff duration $(\mathrm{sec})$ & 47.15 & 45.85 & $\mathrm{n} / \mathrm{a}$ \\
Interpuff interval $(\mathrm{sec})$ & 1.87 & 1.97 & $1.0-2.4$ \\
Cigarette duration $(\mathrm{sec})$ & 60.47 & 61.29 & $18-64$ \\
\hline
\end{tabular}

Note-Ranges were reported in USDHHS (1988, pp. 156-157). TTD, telemetric topography device. 
cury). We then plotted the relation between the known vacuums (measured with a Stoelting pressure gauge) and the digital output of the TTD computer program. The relation was very nearly linear $(r=.99)$.

Together, these findings indicate an accuracy of the TTD that is appropriate for its uses.

\section{Summary}

The TTD offers a less intrusive method of measuring smoking topography that should increase the external validity and generalizability of laboratory smoking samples. Although current microelectronics can be used to further miniaturize the TTD to the size of a commercial cigarette holder (thus creating an almost entirely unobtrusive instrument), two limitations still exist. First, the TTD is unable to measure indices relating to pulmonary exposure. The current device, for example, lacks the capability to assess the volume of smoke inhaled into the lungs or the length of time that the smoker holds the smoke before exhaling. Also, the use of any cigarette holder - no matter how small-is an artificial situation for most smokers. Nevertheless, the TTD can assess most of the topographic variables that influence nicotine consumption. Because the circuitry is self-contained within a small, portable, lightweight canister, it remains relatively unobtrusive, so subjects need not attend to its function. This advance should lead to more valid and generalizable topography data than those obtained with previous instruments.

\section{REFERENCES}

Brandon, T. H., Wetter, D. W., \& BaKer, T. B. (in press). Affect, expectancies, urges, and smoking: Do they conform to models of drug motivation and relapse? Experimental \& Clinical Psychopharmacology.

Creighton, D. E., Noble, M. J., \& Whewell, R. T. (1978). Instruments to measure, record and duplicate human smoking patterns. In R. E. Thorton (Ed.), Smoking behaviour: Physiological and psychological influences (pp. 277-288). London: Churchill Livingston.

Epstein, L. H., Ossip, D. J., Coleman, D., Hughes, J., \& Wisst, W. (1981). Measurement of smoking topography during withdrawal or deprivation. Behavior Therapy, 12, 507-519.

Fredericksen, L. W., Martin, J. E., \& Webster, J. S. (1979). Assessment of smoking behavior. Journal of Applied Behavior Analysis, 12, 653-664.

Fredericksen, L. W., Miller, P. M., \& Petersen, G. L. (1977). Topographical components of smoking behavior. Addictive Behaviors, 2 , 55-61.

Hatsukami, D. K., Morgan, S. F., Pickens, R. W., \& Champagne, S. E. (1990). Situational factors in cigarette smoking. Addictive Behaviors, 15, 1-12.

Hatsukami, D. K., Pickens, R. W., Svikis, D. S., \& Hughes, J. R. (1988). Smoking topography and nicotine blood levels. Addictive Behaviors, 13, 91-95.
Henningfield, J. E., \& Griffiths, R. R. (1979). A preparation for the experimental analysis of human cigarette smoking behavior. Behavior Research Methods \& Instrumentation, 11, 538-544.

Miller, P. M., Fredericksen, L. W., \& Hosford, R. L. (1979). Social interaction and smoking topography in heavy and light smokers. Addictive Behaviors, 4, 147-153.

Ossip-Klein, D. J., Martin, J. E., LomaX, B. D., Prue, D. M., \& Davis, C. J. (1983). Assessment of smoking topography generalization across laboratory, clinical, and naturalistic settings. Addictive Behaviors, 8, 11-17.

Payne, T. J., Schare, M. L., Levis, D. J., Colletti, G. (1991). Exposure to smoking relevant cues: Effects on desire to smoke and topographical components of smoking behavior. Addictive Behaviors, 16, 467-479.

Pickens, R. W., Gust, S. W., Catchings, P. M., \& Svikis, D. S. (1983). Measurement of some topographical aspects of smoking in the natural environment. In J. Grabowsky \& C. S. Bell, (Eds.), Measurement in the analysis and treatment of smoking behavior (NIDA Research Monograph No. 48, DHHS Publication No.[ADM] 831285 , pp. 62-78). Washington, DC: National Institute on Drug Abuse.

Pomerleau, C. S., \& Pomerleau, O. F. (1987). The effects of a psychological stressor on cigarette smoking and subsequent behavioral and physiological responses. Psychophysiology, 24, 278-285.

Puustinen, P., Olkkonen, H., Kolonen, S., \& Tuomisto, J. (1987). Microcomputer-aided measurement of puff parameters during smoking of low- and medium-tar cigarettes. Scandinavian Journal of Laboratory Investigation, 47, 655-660.

RaWbone, R. G., Murphy, K., Tate, M. E., \& Kane, S. J. (1978). The analysis of smoking parameters: Inhalation and absorption of tobacco smoke in studies of human smoking behavior. In R. E. Thorton (Ed.), Smoking behavior: Physiological and psychological influences (pp. 171-194). New York: Churchill Livingstone.

Robinson, J. C., \& Young, J. C. (1980). Temporal patterns in smoking rate and mouth-level nicotine exposure. Addictive Behaviors, $\mathbf{5}$, 91-95.

Tobin, M. J., \& SACKNER, M. A. (1982). Monitoring smoking patterns of low and high tar cigarettes with inductive plethysmography. American Review of Respiratory Disease, 126, 258-264.

U. S. Department of Health and Human Services (1988). The health consequences of smoking: Nicotine addiction. A report of the Surgeon General. Washington, DC: U. S. Government Printing Office.

Wurtele, S. K., \& Martin, J. E. (1987). Assessment of smoking. In T. D. Nirenberg \& S. A. Maisto (Eds.), Developments in the assessment and treatment of addictive behaviors (pp. 115-152). Norwood, NJ: Ablex.

Zacny, J. P., Stitzer, M. L., Brown, F. J., Yingling, J. E., \& GrifFITHS, R. R. (1987). Human cigarette smoking: Effects of puff and inhalation parameters on smoke exposure. Journal of Psychopharmacology \& Experimental Therapeutics, 240, 554-564.

\section{NOTES}

1. For a detailed review of smoking assessment techniques and methods, see Wurtele and Martin (1987).

2. Aquafilter Corporation, Ft. Lauderdale, FL.

(Manuscript received January 3, 1994; revision accepted for publication July $11,1994$. 